\title{
Hubungan Spiritualitas dengan Stres pada Penderita Hipertensi di Poli Jantung RSU dr. H. Koesnadi-Bondowoso
}

\author{
(The Correlation between Spirituality and Stress in \\ Hypertension Patiens at Cardiology Unit of \\ dr. H. Koesnadi Hospital-Bondowoso)
}

\author{
Muhamad Alfian Adyatma, Murtaqib, Baskoro Setioputro \\ Fakultas Keperawatan, Universitas Jember \\ Jl.Kalimantan No. 37 Kampus Tegal Boto Jember. Telp/Fax. (0331) 323450 \\ e-mail: murtaqib999@yahoo.co.id
}

\begin{abstract}
Stress becomes one of the factors causing hypertension. The correlation of stress and hypertension occurs through sympathetic nerve activities, which can gradually increase blood pressure. Spirituality is one of coping to deal with stress. Someone who has a high spiritual level is believed that his belief and relationship with God are better. This study analyzed the correlation between spirituality and stress in hypertension patients at the Cardiology unit of dr. H. Koesnadi Hospital-Bondowoso. The variables were Spirituality and Stress. The research design was observational analytic with a cross-sectional approach with 84 respondents obtained using consecutive sampling technique. The data collection was carried out by giving the Daily Spiritual Experience Scale (DSES) and Perceived Stress Scale (PSS) questionnaire on August 14th-28th 2018. The results of analysis using the Spearman correlation test were $p$ value $=0.001$ and $r=-0,429(p<0,05)$, indicated a significant correlation between spirituality and stress in hypertension patients. A person who has good spirituality can control his chronic disease and help him to manage his conditions patiently, calmly and can determine his life goals. Suggestions for nurses are to be able to provide motivation to patients to accept the disease and improve adherence to the treatment.
\end{abstract}

Keywords: Hypertension, spirituality, stress

\begin{abstract}
Abstrak
Stres menjadi salah satu faktor penyebab hipertensi. Hubungan stres dengan hipertensi terjadi melalui aktivitas saraf simpatis, yang dapat meningkatkan tekanan darah secara bertahap. Spiritualitas merupakan salah satu koping untuk menangani stres. Seseorang yang memiliki spiritual tinggi dipercaya bahwa keyakinan dan hubungan dengan Tuhannya lebih baik. Penelitian ini bertujuan untuk menganalisis hubungan antara spiritualitas dengan stres pada pasien hipertensi di Poli Jantung RSU dr. H. Koesnadi-Bondowoso. Variabel dalam penelitian ini adalah Spiritualitas dan Stres. Desain penelitian ini menggunakan analitik observasional dengan pendekatan cross sectional dengan jumlah sampel 84 responden yang diperoleh dengan teknik consecutive sampling. Pengumpulan data dilakukan dengan memberikan kuesioner Daily Spiritual Experience Scale (DSES) dan Perceived Stress Scale (PSS) pada tanggal 14-28 Agustus 2018. Hasil dengan uji korelasi Spearman yaitu $p$ value $=0,001$ dan $r=-0,429 \quad(p<0,05)$, menunjukkan adanya hubungan yang signifikan antara spiritualitas dengan stres pada penderita hipertensi. Seseorang yang memiliki spiritualitas yang baik dapat mengendalikan penyakit kronisnya dan membantu pasien untuk mengelola kondisinya dengan sabar, tenang dan dapat menentukan tujuan hidupnya. Diharapkan perawat dapat memberikan motivasi kepada pasien agar menerima penyakit serta meningkatkan kepatuhan dalam berobat.
\end{abstract}

Kata kunci: Hipertensi, spiritualitas, stres 


\section{Pendahuluan}

Hipertensi merupakan penyakit kelainan jantung dan pembuluh darah yang ditandai dengan peningkatan tekanan darah sistolik $>140 \mathrm{mmHg}$ dan tekanan darah diastoliknya $>90 \mathrm{mmHg}$ yang dilakukan pada dua kali pengukuran dengan selang waktu lima menit dalam keadaan tenang [1,2]. Penderita hipertensi akan mengalami tekanan darah yang tidak dapat terkontrol hingga menimbulkan komplikasi. Kasus penderita hipertensi biasanya tidak menyadari bahwa dirinya telah menderita hipertensi ketika tekanan darahnya berada di atas batas normal. Di antara penyakit kardiovaskular seperti gagal jantung, henti jantung dan penyakit arteri koroner-perifer pada penderita hipertensi.

Prevalensi penderita hipertensi ada 1 miliar orang didunia. Presentase angka dalam jumlah tesebut penderita hipertensi akan terus meningkat seiring dengan jumlah penduduk yang membesar [3]. Prevalensi hipertensi di Indonesia sebesar $31,7 \%$ dari total penduduk dewasa [4]. Berdasarkan hasil prevalensi penyakit hipertensi esensial atau stres di Provinsi Jawa Timur sebesar 37,4\% [4]. Berdasarkan hasil pengukuran tekanan darah penduduk $\geq 15$ tahun menurut jenis kelamin jumlah laki-laki dan perempuan di Bondowoso yang menderita hipertensi sekitar $18,13 \%$ atau 39.643 penduduk [5].

Berdasarkan hasil studi pendahuluan, Dinas Kesehatan Kabupaten Bondowoso dari 25 Puskesmas seluruh Kabupaten Bondowoso sekitar sebanyak 14.583 orang yang terdiri dari 4.839 lakilaki dan 9.744 perempuan penderita Hipertensi. Laporan data tersebut menunjukkan bahwa Kecamatan Cermee menjadi wilayah dengan hipertensi terbanyak yaitu 1.206 orang, diikuti dengan Kecamatan Prajekan sebesar 336 orang, dan diikuti dengan Kecamatan Tapen sebesar 436 orang. Jumlah tersebut didapatkan karena klien atau pasien hipertensi tersebut melakukan pemeriksaan di Puskesmas Desa masing-masing. Sedangkan data dari Rekamedik RSU dr. $\mathrm{H}$. Koesnadi Kabupaten Bondowoso sekitar sebanyak 395 pasien rawat inap dan sebanyak 3.561 pasien rawat jalan hipertensi pada tahun 2017. Hasil data studi pendahuluan di ruang Poli Jantung sebanyak 6.152 pasien hipertensi rawat jalan pada tahun 2017.

Tekanan darah tinggi dapat disebabkan oleh berbagai macam faktor resiko, salah satunya dapat mengakibatkan stres. Pada saat individu mengalami stres, hormon adrenalin akan dilepaskan dan kemudian akan meningkatkan tekanan darah melalui kontraksi arteri (vasokontriksi) dan peningkatan denyut jantung. Apabila stres berlanjut, tekanan darah akan tetap tinggi sehingga orang tersebut akan mengalami hipertensi [6]. Hubungan antara stres dengan hipertensi diduga terjadi melalui aktivitas saraf simpatis, yang dapat meningkatkan tekanan darah secara bertahap. Apabila stres menjadi berkepanjangan dapat mengakibatkan tekanan darah menjadi tetap tinggi [7]. Hubungan antara stres dengan hipertensi terbukti secara signifikan mempunyai hubungan pada gangguan mental sedang dan gangguan mental berat dapat meningkatkan hipertensi [8].

Beberapa asumsi menyebutkan bahwa orang akan menjadi lebih tertarik dan kembali pada agama di saat mengalami masa sulit bahkan sampai memasuki masa usia lanjut. Spiritualitas melibatkan arti makna hidup dan tidak hanya sebatas pada kepercayaan. Keyakinan dapat didefinisikan sebagai nilai yang dimiliki oleh individu yang menjadi ciri gaya hidup dan tingkah lakunya [9]. Spiritualitas adalah keyakinan dalam hubungannya dengan yang Maha Kuasa dan Maha Pencipta. Menguraikan spiritualitas sebagai suatu yang multidimensi, yaitu dimensi eksistensial, dan dimensi agama [10]. Penyakit dapat dikelola dengan menggunakan praktik dan keyakinan spiritualitas. Praktik dan keyakinan spiritualitas menjadi sebuah mekanisme yang dapat meringankan stres fisiologis dan psikologis seperti sakit dan ketidakberdayaan [11]. Perawatan kesehatan yang berfokus pada psikososial dan spiritual pasien berperan dalam perbaikan dan pemulihan pasien [12]. Keberhasilan seseorang menghadapi perubahan akibat penyakit kronis dapat menguatkan seseorang secara spiritual dan akibatnya individu tersebut akan melakukan evaluasi ulang (re-evaluation) tentang hidupnya. Individu yang mempunyai kekuatan secara spiritual akan membangun identitas diri kembali [13].

Pada saat terjadi stres, penyakit, kehilangan, penyembuhan, atau nyeri menyerang seseorang, kekuatan spiritual dapat membantu seseorang kearah penyembuhan [13]. Pada saat mengalami stres membutuhkan dukungan dari spiritual (keagamaan) yang memberikan ketenangan batiniah [14]. Kehidupan spiritual yang baik akan membantu untuk lebih sabar, pasrah, tenang, damai dan ikhlas dalam menghadapi persoalan, sehingga dapat menekan stres [15]. Pasien menggunakan keyakinan dan 
agama agar menerima kenyataanatas penyakitnya untuk mengelola kondisinya dengan sabar, toleran, mengharap dengan tenang, dan percaya diri untuk masa depan yang baik [16]. Spiritualitas merupakan bagian penting dari kesehatan yang berperan dalam mengendalikan penyakit kronis dan menentukan tujuanhidup [17].

Berdasarkan permasalahan diatas peneliti ingin mengetahui bagaimana hubungan antara spiritualitas dengan stres pada penderita hipertensi.

\section{Metode Penelitian}

Penelitian ini menggunakan penelitian observasional analitik dengan menggunakan metode cross sectional. Teknik sampling yang digunakan dalam penelitian yaitu non-probability sampling dengan caraconsecutive sampling. Jumlah sampel sebanyak 84 responden dengan perhitungan sampel $\mathrm{G}^{*}$ Power 3 menggunakan standar effect size 0,$30 ; \quad \alpha$ errorprobability menggunakan 0,05 ; dan power $(1-\beta$ error probability) menggunakan 0,80 . Kuesioner yang digunakan yaitu DSES (Daily Spiritual Experience Scale) dan (PSS) Perceived Stress Scale. Teknik analisa data menggunakan uji statistik Spearman rank.

\section{Hasil}

\section{Karakteristik Responden}

Karakteristik responden berdasarkan karakteristik pasien menurut agama, jenis kelamin, status pernikahan, tingkat pendidikan, dan pekerjaan dapat dilihat pada Tabel 1 .

Tabel 1. Distribusi responden berdasarkan karakteristik pasien hipertensi di ruang poli jantung RSU dr. H. Koesnadi Kabupaten Bondowoso $(n=84)$

\begin{tabular}{lcc}
\hline Variabel & $\begin{array}{c}\text { Jumlah } \\
(\mathrm{n})\end{array}$ & $\begin{array}{c}\text { Persent } \\
\text { ase }(\%)\end{array}$ \\
\hline Agama & & \\
1. Islam & 84 & 100 \\
2. Non-Islam & 0 & 0 \\
3. Lain-lain & 0 & 0 \\
\hline Total & 84 & 100 \\
\hline 1. Laki-laki & 32 & 38,1 \\
2. Perempuan & 52 & 61,9 \\
\hline Total & 84 & 100 \\
\hline Tingkat pendidikan & & \\
1. Tidak Sekolah & 15 & 17,9 \\
2. SD & 24 & 28,6 \\
\hline
\end{tabular}

\begin{tabular}{lcc}
\hline 3. SMP & 18 & 21,4 \\
4. SMA & 21 & 25,0 \\
5. Perguruan Tinggi & 6 & 7,1 \\
\hline Total & 84 & 100 \\
\hline Pekerjaan & & \\
1. Tidak bekerja & 14 & 42,5 \\
2. Petani & 41 & 5 \\
3. Wiraswasta & 9 & 20 \\
4. Pegawai Swasta & 8 & 12,5 \\
5. PNS & 7 & 20 \\
6. Lain-lain & 5 & 6,0 \\
\hline Total & 84 & 100 \\
\hline Status pernikahan & & \\
1. Menikah & 84 & 100 \\
2. Tidak menikah & 0 & 0 \\
3. Duda/Janda & 0 & 0 \\
\hline Total & 84 & 100 \\
\hline
\end{tabular}

Berdasarkan tabel 1 dapat disimpulkan bahwa penderita hipertensi di ruang poli jantung RSU dr. H. Koesnadi Kabupaten Bondowoso sebagian besar perempuan, beragama islam dan sudah menikah. Sebagian besar yaitu $28,6 \%$ memiliki pendidikan rendah. Sehingga sangat dimungkinkan penderita dalam penelitian ini banyak yang tidak bekerja yaitu $42,5 \%$, walaupun didominasi oleh perempuan, karena hampir setengah penderita berada dalam pengobatan rawat jalan. Rata-rata usia penderita hipertensi penelitian ini menunjukan bahwa rata-rata usia penderita hipertensi dalam penelitian yaitu pada usia setengah baya yaitu 51,50 tahun.

\section{Spiritualitas}

Gambaran spiritulitas pasien hipertensi dapat dilihat pada Tabel 2 dan Tabel 3.

Tabel 2. Nilai rata-rata Spiritualitas Pada Penderita Hipertensi di Ruang Poli Jantung RSU dr. H. Koesnadi Kabupaten Bondowoso $(\mathrm{n}=84)$

\begin{tabular}{lccc}
\hline Variabel & Mean & Median & Min-Maks \\
\hline Spiritualitas & 69,96 & 70,00 & $63-78$ \\
\hline
\end{tabular}

Berdasarkan tabel 2 diatas menunjukkan bahwa responden hipertensi nilai rata-rata spiritualitas adalah 69,96 dengan nilai tengah 70,00 . Nilai min-maks spiritualitas responden adalah 63 dan nilai maksimal 78 .

Tabel 3. Nilai rerata spiritualitas pada penderita hipertensi di ruang poli jantung RSU dr. $\mathrm{H}$. Koesnadi Kabupaten Bondowoso $(n=84)$ 
Adyatma, et al, Hubungan Spiritualitas dengan Stres pada Penderita Hipertensi ....

\begin{tabular}{lccc}
\hline Indikator & Mean & Median & Min-Maks \\
\hline $\begin{array}{l}\text { Kegembira } \\
\text { an dengan } \\
\text { Tuhan }\end{array}$ & 5,190 & 5,000 & $4,0-6,0$ \\
\hline $\begin{array}{l}\text { Menerima } \\
\text { orang lain }\end{array}$ & 4,143 & 4,000 & $3,0-5,5$ \\
\hline
\end{tabular}

Berdasarkan tabel 4 dapat disimpulkan bahwa rata-rata spiritualitas paling tinggi 5,190 pada indikator kegembiraan dengan Tuhan dan rata-rata paling rendah 4,143 pada domain menerima orang lain.

Tabel 4. Distribusi Spiritualitas Pada Penderita Hipertensi di Ruang Poli Jantung RSU dr. H. Koesnadi Kabupaten Bondowoso $(n=84)$

\begin{tabular}{lcc}
\hline Spiritualitas & Jumlah $(\mathrm{n})$ & $\begin{array}{c}\text { Persentase } \\
(\%)\end{array}$ \\
\hline Rendah & 0 & 0 \\
\hline Sedang & 3 & 3,6 \\
\hline Tinggi & 81 & 96,4 \\
\hline Total & 84 & 100 \\
\hline
\end{tabular}

Pada tabel 4 diperoleh hasil $96,4 \%$ penderita hipertensi di ruang poli jantung RSU dr. H. Koesnadi Kabupaten Bondowoso tinggi. Sehingga dapat ditarik kesimpulan bahwa penderita dalam penelitian ini sebagian besar memiliki hubungan yang erat dengan Tuhan dan agama terhadap pengobatan stres yang dialami.

\section{Stres}

Tabel 5 Nilai rata-rata Stres Pada Penderita Hipertensi di Ruang Poli Jantung RSU dr. H. Koesnadi Kabupaten Bondowoso $(\mathrm{n}=84)$

\begin{tabular}{lccc}
\hline Variabel & Mean & Median & Min-Maks \\
\hline Stres & 23,79 & 24,00 & $16-33$ \\
\hline
\end{tabular}

Berdasarkan tabel 5 diatas menunjukkan bahwa responden hipertensi nilai rata-rata stres adalah 23,79 dengan nilai tengah 24,00 . Nilai minmaks stres responden adalah 16 dan nilai maksimal 33.

Tabel 6. Nilai rerata Indikator Stres Pada Penderita Hipertensi di Ruang Poli Jantung RSU dr. $\mathrm{H}$. Koesnadi Kabupaten Bondowoso $(n=84)$

\begin{tabular}{lccc}
\hline Indikator & Mean & Median & Min-Maks \\
\hline $\begin{array}{l}\text { Perasaan } \\
\text { tidak }\end{array}$ & 2,4643 & 2,5000 & $1,75-2,35$ \\
\hline
\end{tabular}

\begin{tabular}{ccccc}
\hline \multirow{2}{*}{ Spiritualitas } & \multicolumn{2}{c}{ Stres } & \multicolumn{2}{c}{ Total } \\
\cline { 2 - 5 } & Rendah & Sedang & Tinggi \\
\hline Rendah & 0 & 3 & 0 & 0 \\
\hline Sedang & 0 & 48 & 3 & 3 \\
\hline Tinggi & 33 & 51 & 81 & 81 \\
\hline Total & 33 & 51 & 84 & 84 \\
\hline
\end{tabular}

Berdasarkan tabel 7 diketahui bahwa mayoritas responden memiliki spiritualitas tinggi total skor tertinggi dari variabel stres yaitu pada kondisi stres sedang sejumlah 51 responden dari 84 responden

\section{Hubungan Spiritualitas dengan Stres Pada Penderita Hipertensi}

Tabel 7. Hubungan Spiritualitas Dengan Stres Pada Penderita Hipertensi di ruang poli jantung RSU dr. $H$. Koesnadi Kabupaten Bondowoso $(n=84)$

\begin{tabular}{lcc}
\hline Variabel & $\boldsymbol{p}$ value & $\boldsymbol{r}$ \\
\hline $\begin{array}{l}\text { Hubungan Spiritualitas- } \\
\text { Stres }\end{array}$ & 0,001 & $-0,429$ \\
\hline
\end{tabular}

Berdasarkan tabel 7 dapat disimpulkan bahwa ada hubungan yang signifikan antara variabel spiritualitas dengan stres penderita hipertensi $(p$ value $<0,05)$. 


\section{Pembahasan}

\section{Spiritualitas}

Hasil yang diperoleh dalam penelitian ini yaitu lebih dari separuh penderita hipertensi memiliki spiritualitas yang tinggi terhadap stres. Penelitian yag dilakukan oleh peneliti sebelumnya yang mayoritas respondennya 64 orang $(62,7 \%)$ memiliki tingkat spiritualitas tinggi [18]. Faktor-faktor yang dapat mempengaruhi spiritualitas yaitu usia, jenis kelamin, status menikah, latar belakang budaya serta kondisi krisis dan perubahan. Faktor yang pertama adalah usia. Seiring bertambahnya tahap perkembangan seseorang diikuti dengan berkembangnya spiritualitas yang dimulai dari bayi hingga lansia [19]. Faktor yang kedua adalah jenis kelamin. Perempuan lebih terlibat dalam aktivitas amal dan peduli secara aktif terhadap kegiatan sosial dibandingkan dengan laki-laki [20]. Perempuan lebih menekan pada penyelesaian masalah, penyerahan, kelembutan, pengasuhan dan nilai ekspresif lainnya yang sesuai dengan penekanan agama, bahwasannya perempuan mempunyai sifat spiritualitas yang tinggi [21]. Faktor yang ketiga adalah status menikah. Responden yang sudah menikah mendapatkan dukungan dari pasangannya baik dalam menjalankan perawatan kesehatan maupun aktivitas keagamaan.

Skor indikator spiritualitas responden tertinggi yaitu kegembiraan dengan Tuhan. Pada kondisi tersebut responden merasakan kehadiran Tuhan dan menegaskan bahwa mereka tidak sendiri [2]. Penelitian pada 299 pasien kronis di Amerika Serikat menyebutkan bahwa pasien yang patuh terhadap iman mempunyai kesejahteraan yang baik dan lebih menunjukkan strategi koping yang positif [36]. Kasih sayang melalui orang lain disebabkan oleh terdapat keyakinan bahwa Tuhan bertindak atas diri manusia melalui orang lain, sehingga berkah, rejeki, dan kebahagiaan dapat diperoleh melalui interaksi dengan orang lain. Hubungan dengan Tuhan bermanfaat dalam membentuk perilaku yang positif bagi seorang individu [23]

Skor indikator spiritualitas terendah pada penelitian ini yaitu menerima orang lain. Hal yang dimaksudkan disini adalah perasaan belas kasihan dan sikap menerima orang lain sekalipun ketika berbuat kesalahan [22]. Penelitian sejalan pada pasien kronis dihasilkan nilai rata-rata dimensi hubungan dengan sesama lebih rendah dibandingkan dengan dimensi agama [24]. Hubungan dengan orang lain atau dengan sesama individu dapat direalisasikan dengan saling berbagi waktu, bertukar sumber informasi dan pengetahuan; merawat anggota keluarga yang sedang sakit; percaya mengenai kehidupan dan kematian seperti melayat jika ada yang meninggal serta sering bersilaturahim dengan sesama [25].

\section{Stres}

Hasil penelitian ini menunjukan bahwa rata-rata memiliki stres sedang. Didapatkan hasil penelitian responden 20 orang $(66,7 \%)$ mengalami stres sedang [29]. Persepsi dan pengalaman individu terhadap perubahan besar dapat menimbulkan stres. Stres merupakan suatu fenomena yang dapat mempengaruhi semua dimensi dalam kehidupan individu [13]. Stres dapat menimbulkan perubahan secara fisologis, psikologis, dan perilaku pada individu yang mengakibatkan berkembangnya suatu penyakit [26].

Faktor yang dapat mempengaruhi stres adalah faktor biologis dan sosial psikologik. Selain itu, faktor yang mempengaruhi stres seseorang yaitu keyakinan diri [30]. Faktor biologis yang mempengaruhi stres misalnya penyakit yang sebelumnya pernah diderita membuat suatu organ tertentu menjadi lebih lemah dari pada organ lainnya, hingga akhirnya rentan dan mudah mengalami kerusakan ketika individu tersebut dalam kondisi tertekan dan tidak fit [27]. Selanjutnya faktor sosial psikologik yaitu labeling (penamaan) dan prasangka, ketidakpuasan terhadap diri sendiri, pekerjaan, konflik peran, harga diri yang rendah, perubahan ekonomi, dan emosi yang negative [31]. Faktor yang terakhir adalah keyakinan diri yang mempunyai arti kehidupan terjadinya stres pada diri seseorang yang dalam hal ini bisa menyebabkan perubahan dalam kehidupan individu baik anak, remaja, atau dewasa sehingga orang itu mengadakan adaptasi stresor yang timbul [37]

Skor indikator stres responden tertinggi yaitu perasaan tidak terkontrol. Penelitian ini sejalan pada 64 orang dari 120 responden di Kota Selong Lombok Timur menyebutkan individu tujuan hidup paruh baya dan mengalami stres yang dapat mengakibatkan masalah [28]. Dampak negatif bagi psikologis ini yaitu gelisah, emosi yang tidak stabil, marah yang tidak terkontrol dan bahkan dapat menyebabkan stres yang lebih serius yakni kecemasan, serta dapat menimbulkan depresi [28]. Salah satu tipe kepribadian merupakan faktor penting dalam menentukan stres, dimana sebagian orang dapat melewati stres yang dialami namun sebagian orang lagi kurang mampu dalam mengatasi stres sehari-hari [32].

Skor indikator stres terendah pada 
penelitian ini yaitu perasaan tertekan. Gejala secara psikologis individu yang mengalami stres, antara lain ditandai oleh perasaan selalu gugup dan cemas, peka dan mudah tersinggung, gelisah, kelelahan yang hebat, enggan melakukan kegiatan, kemampuan kerja dan penampilan menurun, perasaan takut, pemusatan diri yang berlebihan, hilangnya spontanitas, mengasingkan diri dari kelompok, dan pobia [34].

Perasaan selalu gugup dan cemas, merupakan indikasi individu yang mengalami stres saat menghadapi permasalahan. Namun di sisi lain, individu tersebut juga berharap bahkan menuntut pasangannya agar dapat berubah. Ketika harapannya tidak terpenuhi, individu akan semakin kecewa, lalu timbul konflik dan merasa tertekan. Indikasi tersebut merupakan gejala stres secara kualitas psikologis pada kepribadian tipe A yang berupa selalu bergerak, tidak sabaran, melakukan dua hal dalam satu waktu, tidak bisa menikmati waktu luang dengan nyaman dan secara konstan sangat merasa tertekan dengan waktu [23].

\section{Hubungan Spiritualitas Dengan Stres Penderita Hipertensi}

Hasil penelitian ini menunjukan bahwa adanya hubungan antara spiritualitas dengan stres pada penderita hipertensi di Poli Jantung RSU dr. H. Koesnadi Kabupaten Bondowoso. Penelitian mengenai hubungan efikasi diri dengan tingkat stres pada pasien hipertensi bahwa terdapat hubungan yang signifikan antara stres dengan kejadian hipertensi dan dibutuhkan derajat tinggi kesehatan dan keyakinan diri pasien untuk bisa mengatasi stres [37]. Penelitian lain mengenai analisis pengaruh stres terhadap kekambuhan penderita hipertensi dan didapatkan beban fikiran, merasa pusing serta susah tidur, sehingga untuk menjaga kondisi psikologis pasien selain itu juga mengatur tentang pola makan yang baik dan mengindari perilaku merokok [39]

Seseorang yang mempunyai spiritualitas yang baik maka akan terhindar dari stres dan dapat mengatasi permasalahan yang terjadi dalam hidupnya. Penelitian lain juga mengenai hubungan spiritualitas dengan mekanisme koping pada penderita penyakit kronis bahwa terdapat hubungan yang signifikan antara spiritualitas dengan penyakit kronis dan memberikan makna dan tujuan hidup serta meningkatkan strategi koping dalam mengatasi stres yang disebabkan akibat tediagnosis penyakit kronis [40]. Penelitian ini dukung oleh penelitian lainnya mengenai hubungan spiritualitas dengan tekanan darah tinggi pada lansia penderita hipertensi bahwa terdapat hubungan yang siginifikan antara spiritualitas dengan tekanan darah tinggi pada lansia penderita hipertensi dan memberikan efek relaksasi serta meningkatkan kedekatan seseorang dengan Tuhannya dengan cara beribadah, puasa dan zakat akan memberikan efek positif bagi tubuh dalam menangani stres pada tekanan darah tinggi lansia [41].

Apabila spiritualitas individu baik namun stres atau trauma masih terjadi selama proses perkembangan dapat mengakibatkan tiga kondisi, yaitu perubahan persepsi diri, perubahan hubungan dengan orang lain, serta perubahan filosofis mengenai prioritas, apresiasi, dan spiritualitas. Penurunan produktivitas dan stres merupakan proses resiprokal (timbal balik yang berkelanjutan) sehingga ketika seseorang merasa sangat bergantung pada orang lain, maka akan mengalami stres karena merasa tidak lagi mampu mengerjakan sesuatu secara mandiri.

Seseorang akan menjadi lebih tertarik dan kembali pada agama di saat mengalami masa sulit dan mereka menjadi lebih religius. Religiusitas dan spiritualitas merupakan sebuah aspek multidimensional yang melibatkan kognisi, perasaan, dan perilaku termasuk aspek positif dan negatif dari relasi antara individu dengan Sang Pencipta [42]. Spiritualitas merupakan salah satu koping individu untuk menangani stres dan pengambilan keputusan pengobatan [43]. Hasil yang sama juga diungkapkan bahwa kesejahteraan spiritual saat ini dan pengalaman relijius masa lalu berhubungan dengan gejala kecemasan dan depresi [43].

Pada saat terjadi stres, penyakit, kehilangan, penyembuhan, atau nyeri menyerang seseorang, kekuatan spiritual dapat membantu seseorang kearah penyembuhan [13]. Pada saat mengalami stres akan membutuhkan dukungan dari spiritual yang memberikan ketenangan batiniah [14]. Kehidupan spiritual yang baik akan membantu untuk lebih sabar, pasrah, tenang, damai dan ikhlas dalam menghadapi persoalan, sehingga dapat menekan tingkat stres [15].

\section{Simpulan dan Saran}

Dalam penelitian ini terdapat hubungan yang signifikan antara spiritualitas dengan stres. Tingginya spiritualitas penderita hipertensi menunjukkan perempuan sebagai responden paling banyak dari pada laki-laki. Pekerjaan responden sebagian besar petani, status pernikahan semua menikah, dan beragama islam. Terkait hubungan spiritualitas dengan stres 
yaitu dengan bagaimana responden mengatasi masalahnya sendiri, lingkungan sekitar, orang lain dan Tuhan serta agama yang dianutnya. Responden dalam penelitian ini memiliki spiritualitas yang tinggi dan mengalami stres sedang. Dukungan baik dari orang terdekat kepada pasien diharapkan dapat membuat pasien menerima penyakit yang dideritanya. Hubungan personal dapat dibangun dari hal kecil, seperti pemberian dukungan, mendengarkan keluhan pasien ketika ada masalah dan untuk pasien sendiri yaitu dengan membangun pendirian yang positif.

Saran bagi keluarga dan orang terdekat untuk memberikan dukungan berupa motivasi dan perilaku yang tidak mendiskriminasi dari keluarga diharapkan mampu meningkatkan semangat penderita hipertensi untuk percaya dan yakin terhadap Tuhan dan agama yang dianutnya. Petugas kesehatan dapat berperan dalam hal ini dengan cara memberikan pendidikan kesehatan cara memberikan motivasi kepada pasien agar menerima penyakit serta meningkatkan kepatuhan dalam berobat.

\section{Daftar Pustaka}

[1] Marliani L, Tantan HS. 100 Questions and answers hipertensi. Jakarta. Kelompok Gramedia; 2007

[2] Indonesia. Departemen Kesehatan Republik Indonesia. Profil Kesehatan Indonesia. Jakarta: Pusdatin Kementrian Kesehatan Republik Indonesia; 2014

[3] World Health Organization (WHO). Hypertension fact sheet. Departement of Sustainable Development and Health Enviroments. World Health Organization (WHO); 2011

[4] Indonesia. Departemen Kesehatan Republik Indonesia. Pedoman teknis penemuan dan tatalaksana hipertensi. Jakarta: Direktorat Jendral PP \& PL; 2008

[5] Indonesia. Dinas kesehtan Provinsi Jawa Timur. Profil Kesehatan Provinsi Jawa Timur. 2015

[6] South M. Hubungan gaya hidup dengan kejadian hipertensi di Puskesmas Kolongan Kecamatan Kalawat Kabupaten Minahasa Utara. E-journal Keperawatan. [internet] 2014. [2018 Februari 24];2(1). Available from : https://ejournal.unsrat.ac.id/index.php/jkp/artic le/view/4055/3571

[7] Yundini. Faktor resiko terjadinya hipertensi. [internet] Jakarta: Warta pengendalian penyakit tidak menular; 2006 [cited 25 Februari 2018]. Available from:
http://www.Mail-archive.comaboutHtml

[8] Sarwanto, et al. Prevalensi penyakit hipertensi penduduk di Indonesia dan faktor yang beresiko. Buletin Penelitian sistem kesehatan. 2009 April; 12 (2): 154162.

[9] Panzini RG et al. Quality of life and spirituality. Rev Psiq Clin. [internet] 2017. [cited 4 April 2018];34(1) Available from: http://www.lume.ufrgs.br

[10] Hamid. Buku ajar Aspek Spiritual dalam Keperawatan. Widya medika: Jakarta; 1999

[11] Harvey IS, Silverman M. The Role of Spirituality in the Selfmanagement of Chronic Illness among Older African and Whites. J Cross Cult Gerontology. [internet] 2013. [cited 26 Mei 2018]; 22(2):205-220. Available from: https://www.ncbi.nlm.nih.gov

[12] Bussing A, Koenig HG. Spiritual Needs of Patients with Chronic Diseases. Journal of religions. [internet] 2010. [cited 28 Maret 2018];1:18-27. Available from: www.mdpi.com/2077-1444/1/1/18

[13] Potter PA, Perry AG. Buku ajar fundamental keperawatan: konsep, proses dan praktik edisi 4. Jakarta: EGC; 2005

[14] Syam A. Hubungan antara kesehatan spiritual dengan kesehatan jiwa pada lansia muslim di sasana tresna werdha Kbrp Jakarta Timur. Tesis. Jakarta: Program Magister IImu Keperawatan Kekhususan Keperawatan Jiwa Fakultas IImu Keperawatan Universitas Indonesia; 2010

[15] Kasih. Etika kerja dan kecerdasan spiritual serta kepuasan kerja jururawat. Kasih. 25 September 2009. Available from: http://www.scribd.com/doc/20211704/EtikaKerja-DanKecerdasan-Spiritual-SertaKepuasan-Kerja-Jururawat

[16] Shahrbabaki PM, Nouhi E, Kazemi M, Ahmadi F. Spirituality: A Panacea for Patients Coping with Heart Failure. International Journal of Community Based Nursing and Midwifery. [internet] 2017. [cited 21 Februari 2018. 5(1);38-48. Available from: http://kmu.ac.ir/lmages/UserFiles/1010/file/ \%D9\%85\%D9\%86\%DA\%AF\%D9\%84\%DB \%8C\%D8\%A7\%D9\%863.pdf

[17] Zareipour M, Khazir Z, Valizadeh R, Mahmoodi H, Ghojogh MG. The Association between Spiritual Health and Blood Sugar Control in Elderly Patients 
Adyatma, et al, Hubungan Spiritualitas dengan Stres pada Penderita Hipertensi ....

with Type 2 Diabetes. Elderly Health Journal. [internet] 2016. [cited 13 April 2018]. 2(2);6772. Available from: http://ehj.ssu.ac.ir/article1-66-en.pdf

[18] Saman AA, Kusuma, H. Gambaran kebutuhan spiritualitas pasien gagal jantung di instalasi elang RSUP Kariadi Semarang. Artikel Jurnal Mahasiswa 2017.

[19] Carson, Koenig. Spiritual Dimensions Of Nursing Practice. Wb Saunders: Philadhepia; 2008.

[20] Bryant, AR, Nix, PD. Acute \& Chronic Wounds: Current Management Concepts, Third Edition. St. Louis, Missouri. Mosby; 2007

[21] Luqman NA. Puri, Tanwar K. Gender Differences In Spiritual Personality. International Journal Of Multidisciplinary And Current Research. 2015. 3:719-722.

[22] Underwood, LG. Ordinary Spiritual Experience: Qualitative Research, Interpretive Guidelines, and Population Distribution for the Daily Spiritual Experience Scale. Archive for the Psychology of Religion/ Archivfür Religions psychologie. [internet] 2006. [cited 5 April 2018];28(1):181-218. Available from: http://www.dsescale.org/OrdSpirExp.pdf

[23] Ningrum, AW. Gambaran spiritualitas pada pasien diabetes mellitus di Puskesmas Kampung Baru Medan. Skripsi. Medan: Fakultas Keperawatan USU. 2014

[24] Baby S, Khan O. Spiritual Well-Being among Diabetic Patients. The International Journal of Indian Psychology. [internet] 2016. [cited 23 Desember 2018]. 3(4);65-71. Available from: http://www.ijip.in/Archive/v3i4/18.01.141.2016 0304.pdf

[25] Hamid AY. Bunga rampai asuhan keperawatan kesehatan jiwa. [internet]. EGC: Jakarta; 2008. [cited [25 Mei 2018]. Available from Netlibrary: https://books.google.co.id

[26] Hawari D. Manajemen Stress, Cemas Dan Depresi. Jakarta: Balai penerbit FKUI; 2008

[27] Sarafino EP. Health Psychology: Biopsychosocial Interaction. New York: John Wiley \& Sons Inc; 1998.

[28] Rohim R. Hubungan antara spiritualitas dan manajemen stres pada individu paruh baya. Skripsi. Fakultas Psikologi Universitas Muhammadiyah Malang; 2016.

[29] Sartika. Hubungan tingkat stress dengan tingkat hipertensi pada dewasa madya di niten nogotirto gamping Sleman Yogyakarta. Skripsi. Universitas Aisyiyah Yogyakarta; 2014

[30] Sunaryo. Psikologi untuk keperawatan.
Jakarta: EGC; 2013.

[31] Rasmun. Stress Koping dan adaptasi. Jakarta: Cv. Sagung Seto; 2004.

[32] Dumitru, VM, Cozman D. The relationship between stress and personality factors. International Journal of the bioflux Society. 2012; 4(1): 34-39.

[33] Lachman ME. Development in Midlife. Annual Review of Psychology. 305-331; 2004.

[34] Waitz, Grete Stromme, Sigmund, Railo, Willi S. Conquer Stress with Grete Waitz, (terjemahan Sinta AW). Bandung: Angkasa; 1983.

[35] Dehning DO, Nelson LA, Stewart JA, Stewart WC. Does Religious Adherence Help Diabetic Patients' Well-Being?. JCN. [internet] 2013. [cited 23 Desember 2018]. Available http://stage.teleiosresearch.com/wpcontent/uploads/2017/07/CV-408Religionand-diabetes-JCN-2013.pdf

[36] Rosa, NI. Hubungan efikasi diri dengan tingkat stres pasien hipertensi di poli jantung RSD Dr. Soebandi Jember. Skripsi. Program Studi IImu Sarjana Keperawatan Fakultas Keperawatan Universitas Jember; 2018.

[37] Hawari D. Alquran ilmu kedokteran jiwa dan kesehatan mental. Jakarta: Dana Bhakti Yasa; 1997.

[38] Muhlisin A, Laksono, R, A. Analisis pengaruh faktor stres terhadap kekambuhan penderita hipertensi di Puskesmas Bendosari Sukoharjo Mahasiswa Program Studi IImu Keperawatan Fakultas IImu Kesehatan Universitas Muhammadiyah Surakarta. ISSN: 2338-2694; 2013

[39] Rohmin, NS. Hubungan spiritualitas dengan strategi koping pada pasien diabetes melitus tipe 2 di wilayah kerja Puskesmas Jenggawah Kabupaten Jember. Skripsi. Program Studi Sarjana Keperawatan Fakultas Keperawatan Universitas Jember; 2018.

[40] Almarwah IM, Utami S, Dewi SR. Hubungan spiritualitas dengan tekanan darah pada lansia penderita hipertensi di wilayah kerja Ambulu Kabupaten Jember. [internet]. 2018. [cited 15 Desember 2018). Universitas Muhammadiyah Jember.

[41] Werdel MB, Dy-Liacco GS, Ciarrocchi JW, Wicks RJ, Breslford GM. The Unique Role Of Spirituality In The Process Of Growth Following Stress And Trauma. Pastoral 
Adyatma, et al, Hubungan Spiritualitas dengan Stres pada Penderita Hipertensi ....

Psychology [internet]. 2014. [cited [20 Desember 2018];63(1),57-71. Available from: Https://Doi.Org/10.1007/S11089-013-0538-4

[42] Johnson KS, Tulsky JA, Hays JC, Arnold RM, Olsen MK, Lindquist JH, Steinhauser KE. (2011). Which Domains Of Spirituality Are Associated With Anxiety And Depression In Patients With Advanced IIIness?. Journal Of General Internal Medicine. [internet]. 2011. [cited [19 Desember 2018];26(7),751-758. Available from: Http://Doi.Org/10.1007/S11606-011-1656-2

[43] Jaelani AR. Hubungan stres dengan efikasi diri pada pasien diabetes melitus tipe 2 di wilayah kerja Puskesmas Patrang Kabupaten Jember. Skripsi. Program Studi IImu Keperawatan Universitas Jember; 2016 